\title{
Basal Host Resistance of Barley to Powdery Mildew: Connecting Quantitative Trait Loci and Candidate Genes
}

\author{
Reza Aghnoum, ${ }^{1}$ Thierry C. Marcel, ${ }^{1}$ Annika Johrde, ${ }^{2}$ Nicola Pecchioni, ${ }^{3}$ Patrick Schweizer, ${ }^{2}$ and \\ Rients E. Niks ${ }^{1}$ \\ ${ }^{1}$ Laboratory of Plant Breeding, Graduate School for Experimental Plant Sciences, Wageningen University, \\ Droevendaalsesteeg 1, 6708 PB Wageningen, the Netherlands; ${ }^{2}$ Leibniz-Institute of Plant Genetics and Crop Plant \\ Research (IPK), Corrensstraße 3, 06466 Gatersleben, Germany; ${ }^{3}$ Dipartimento di Scienze Agrarie e degli Alimenti, \\ Università di Modena e Reggio Emilia, Via Amendola 2, I-42100 Reggio Emilia, Italy
}

Submitted 26 June 2009. Accepted 17 September 2009.

The basal resistance of barley to powdery mildew (Blumeria graminis f. sp. hordei) is a quantitatively inherited trait that is based on nonhypersensitive mechanisms of defense. A functional genomic approach indicates that many plant candidate genes are involved in the defense against formation of fungal haustoria. It is not known which of these candidate genes have allelic variation that contributes to the natural variation in powdery mildew resistance, because many of them may be highly conserved within the barley species and may act downstream of the basal resistance reaction. Twenty-two expressed sequence tag or cDNA clone sequences that are likely to play a role in the barley-Blumeria interaction based on transcriptional profiling, gene silencing, or overexpression data, as well as mlo, Ror 1 , and Ror 2 , were mapped and considered candidate genes for contribution to basal resistance. We mapped the quantitative trait loci (QTL) for powdery mildew resistance in six mapping populations of barley at seedling and adult plant stages and developed an improved high-density integrated genetic map containing 6,990 markers for comparing QTL and candidate gene positions over mapping populations. We mapped 12 QTL at seedling stage and 13 QTL at adult plant stage, of which four were in common between the two developmental stages. Six of the candidate genes showed coincidence in their map positions with the QTL identified for basal resistance to powdery mildew. This co-localization justifies giving priority to those six candidate genes to validate them as being responsible for the phenotypic effects of the QTL for basal resistance.

Basal resistance has been used to describe a low-level penetration resistance not due to hypersensitivity expressed in "susceptible" plants (Collins et al. 2003). In the barley-powdery mildew interaction, basal resistance is associated with the formation of cell-wall appositions, so-called papillae, at the fungal penetration sites that prevent the formation of fungal haustoria.

Corresponding author: Rients E. Niks, E-mail: rients.niks@wur.nl

Current address of T. C. Marcel: UMR 1290 INRA AgroParisTech BIOGER-CPP, INRA Centre de Recherche de Versailles-Grignon, Route de Saint Cyr (RD 10), 78026 Versailles Cedex, France.

* The $\boldsymbol{e}$-Xtra logo stands for "electronic extra" and indicates that five supplementary tables and a supplementary figure are published online. Also, Figure 2 appears in color online.
This resistance is considered to be an important and potentially durable type of resistance. Nevertheless, it is poorly understood at the molecular level. A molecular framework for the evolution of plant immunity has been proposed by Jones and Dangl (2006) and is now a widely accepted hypothesis. Based on this hypothesis, basal defense represents pathogen-associated molecular pattern (PAMP)-triggered defense responses that are able to defeat most would-be pathogens, except those that have evolved tools to overcome PAMP-triggered immunity (PTI) by reprogramming plant cells, resulting in partial or complete suppression of defense by means of effectors.

Gene expression studies, high-throughput gene silencing, transient transformation, and large-scale mutation assays have been very productive in indicating candidate genes for traits of interest, including disease resistance. To identify genes that influence barley-Blumeria interactions in host and nonhost combinations, a high-throughput RNA interference (RNAi) system for transient-induced gene silencing (TIGS) as well as a transient overexpression in single epidermal cells of barley have been developed (Schweizer et al. 1999; Douchkov et al. 2005; Ihlow et al. 2008). Using this system, the function of 930 barley candidate genes, including 693 upregulated genes and 101 resistance-gene analogs expressed in barley epidermis, have been tested for their effect on nonhost resistance of barley to wheat powdery mildew and on basal host resistance. The roles of 43 genes in nonhost resistance, basal resistance, or mlo-mediated resistance of barley have been confirmed by using this method (Dong et al. 2006; Zimmermann et al. 2006; Johrde and Schweizer 2008; P. Schweizer, unpublished).

The recessive allele of the Mlo locus in barley mediates a race-nonspecific resistance to barley powdery mildew. Both mlo resistance and basal resistance share the same mechanism of defense (i.e., both are "papilla-associated") (Trujillo et al. 2004; Schweizer 2007). Mutational approaches revealed that two genes (Rorl and Ror2) are required for full expression of mlo resistance (Freialdenhoven et al. 1996). These two genes have also been implicated in basal penetration resistance of barley expressed in susceptible ( $M l o$ ) genotypes (Collins et al. 2003). Therefore, mlo, Ror 1 , and Ror 2 can be considered candidate genes for involvement in the basal resistance of barley to powdery mildew.

Candidate gene analysis is based on the hypothesis that genes with known function could correspond to loci controlling traits of interest (Pflieger et al. 2001). This approach has been widely applied to genetic dissections of complex and quantitative traits (Zhu and Zhao 2007). For plant geneticists, a 
candidate gene is any gene putatively involved in trait variation, based on its biological function, map position, or expression pattern (Pflieger et al. 2001). Ideally, the list of candidate genes to explain a particular phenotype can be shortened by following a prioritization approach, which consists of combining information on the function, position, and expression of the genes involved (Zhu and Zhao 2007). However, candidate genes should finally be validated through fine-mapping, positional cloning, and genetic transformation.

Candidate genes whose expression level is correlated with changes in haustorium formation as shown after overexpression or silencing are not necessarily polymorphic between plants with different levels of basal resistance. Such genes may act downstream of the basal resistance reaction and, hence, not be the determinants of the natural variation in levels of basal resistance. The study of the inheritance of natural variation can be considered an alternative approach to elucidate the functional role of candidate genes in a given phenotype (MitchellOlds and Schmitt 2006).

In the present study, we mapped quantitative trait loci (QTL) that affect the level of basal resistance in six barley mapping populations and compared their map positions with those of 22 markers derived from gene sequences that were either found to be pathogen induced or that produced a phenotype upon RNAi or overexpression during the interaction of barley with powdery mildew. As explained above, we also considered the $m l o$, Ror 1 , and Ror 2 genes to be candidate genes. In order to prioritize the candidate genes, we combined their expression and function data with their map position relative to the QTL. Finally, we determined whether or not QTL tended to map to the major gene loci for resistance to powdery mildew.

\section{RESULTS}

\section{The new barley integrated map.}

The new barley integrated map contains 6,990 morphological or molecular markers covering a total genetic distance of 1,093 centimorgans $(\mathrm{cM})$, which is similar to previously reported barley integrated genetic maps (Table 1). The framework map contains 823 bridge markers for the barley chromosomes in total (i.e., 94 on chromosome $1 \mathrm{H}, 149$ on $2 \mathrm{H}, 131$ on $3 \mathrm{H}, 85$ on $4 \mathrm{H}, 126$ on $5 \mathrm{H}, 116$ on $6 \mathrm{H}$, and 122 on $7 \mathrm{H}$ ) and covers a genetic distance of $1,051 \mathrm{cM}$. The most represented types of molecular markers on this integrated map are restriction fragment length polymorphism (RFLP) (20\%), amplified fragment length polymorphism (AFLP) (20\%), simple-sequence repeat (SSR) (9\%), diversity arrays technology (DArT) (19\%) and transcript-derived marker (TDM) $(23 \%)$ (=91\% of all markers). RFLP and AFLP marker techniques are not used as commonly anymore but the integration of such markers with more modern types of markers allows the integration of past and present data collected from many different mapping popula- tions as well as the selection of markers or candidate genes linked to a particular trait locus in any of these populations. More than $43 \%$ of the markers on the present barley integrated map target expressed sequence tags (EST) or gene sequences (gene-targeted markers [GTM]) and can be used for candidate gene identification (Rostoks et al. 2005; Marcel et al. 2007b) or to perform synteny analyses (Rostoks et al. 2005; Stein et al. 2007). The Steptoe/Morex (StMo) map contributed more than half of the total number of markers $(3,561$ markers) to the integrated map, most of them coming from the recently released array-based marker data sets (Wenzl et al. 2006; Potokina et al. 2008). The very low percentage of errors and high quality of these marker data greatly increase the reliability of our integrated map. The present integrated linkage map was aligned with the Marcel and associates (2007b) map and with the TDM-based map from Potokina and associates (2008) in order to compare their locus order (Supplementary Fig. S1). The marker order between the present integrated map and the TDMbased map was highly consistent, with only a few localized inversions pinpointing small inaccuracies inherent to map integration projects (Jackson et al. 2008). The marker order was also consistent with the integrated map of Marcel and associates (2007b), with the exception of some reordering between several AFLP markers mapped at the telomeres of chromosomes 5HL and $6 \mathrm{HL}$ in the Cebada Capa/SusPtrit (CCSu) population. An inspection of graphical genotypes mostly agreed with the marker order on the present integrated map. The constructed barley integrated map is available as supplemental material (Supplementary Table S2) and has been posted on the GrainGenes website.

\section{QTL mapped at the seedling stage.}

The infection frequency of powdery mildew in detached seedling leaf tests exhibited continuous variation in all six mapping populations that suggests multigenic inheritance. In all tested mapping populations, transgressive segregation toward resistance and toward susceptibility were observed (Fig. 1), indicating that the resistance and susceptibility alleles were contributed by both parents. The number, genomic position on the barley integrated map, and effects of QTL associated with basal resistance to powdery mildew at seedling stage are summarized in Supplementary Table S3 and Figure 2. In total, 12 QTL were mapped that affected the infection frequency (number of colonies on $2-\mathrm{cm}^{2}$ leaf area) at seedling stage in six mapping populations. The mapped QTL were found on all chromosomes. Only one QTL on chromosome 5H (Rbgq15) was in common between Vada/SusPtrit (VaSu) and L94/Vada (LnVa) populations. The phenotypic variation explained by the QTL ranged from 6.2 to $24.8 \%$. The log-likelihood ratio (LOD) scores of QTL were generally low $(\leq 6.1)$. Our results indicate a high level of diversity in QTL involved in powdery mildew resistance at seedling stage in barley.

Table 1. Comparison of several (integrated) linkage maps published for barley

\begin{tabular}{|c|c|c|c|c|c|c|c|c|c|c|}
\hline \multirow[b]{2}{*}{ Reference } & \multirow[b]{2}{*}{ Map length (cM) } & \multirow[b]{2}{*}{ No. of loci } & \multicolumn{7}{|c|}{ Average locus number per centimorgan (cM) } & \multirow[b]{2}{*}{ Contributing populations ${ }^{\mathrm{a}}$} \\
\hline & & & 1H & $2 \mathrm{H}$ & $3 \mathbf{H}$ & $4 \mathbf{H}$ & $5 \mathbf{H}$ & $6 \mathrm{H}$ & $7 \mathbf{H}$ & \\
\hline Rostoks et al.2005 & 1,211 & 1,237 & 0.9 & 1.1 & 1.0 & 1.1 & 0.9 & 1.0 & 1.2 & LiHs, OWBs, StMo \\
\hline Wenzl et al.2006 & 1,161 & 2,935 & 2.8 & 3.1 & 2.5 & 1.9 & 2.0 & 2.5 & 3.0 & $\begin{array}{l}\text { BaCP, ClSa, DaZh, FoCI, FrSt, IgAt, PaTa, } \\
\text { StMo, TXFr, YeFr }\end{array}$ \\
\hline Marcel et al.2007 & 1,081 & 3,258 & 2.6 & 3.7 & 3.3 & 2.4 & 2.3 & 2.9 & 3.8 & LnVa, VaSu, StMo, OWBs, IgFr, CCSu \\
\hline Stein et al.2007 & 1,118 & 1,055 & 1.0 & 1.1 & 0.9 & 0.8 & 0.9 & 0.8 & 1.2 & StMo, OWBs, IgFr \\
\hline Potokina et al.2008 & 1,010 & 1,596 & 1.3 & 1.8 & 1.9 & 1.3 & 1.4 & 1.5 & 1.7 & StMo \\
\hline This article & 1,093 & 6,990 & 6.4 & 7.9 & 6.9 & 4.5 & 5.7 & 5.9 & 7.3 & LnVa, VaSu, StMo, OWBs, IgFr, CCSu, NuTr \\
\hline
\end{tabular}

${ }^{a}$ LiHs (Lina/Hordeum spontaneum HS92); OWBs (Oregon Wolfe Barleys); StMo (Steptoe/Morex); BaCP (Barque-73/CPI71284-48); ClSa (Clipper/ Sahara); DaZh (Dayton/Zhepi2); FoCI (Foster/CI4196); FrSt (Fredickson/Stander); IgAt (Igri/Atlas68); PaTa (Patty/Tallon); TXFr (TX9425/Franklin); YeFr (Yerong/Franklin); LnVa (L94/Vada); VaSu (Vada/SusPtrit); IgFr (Igri/Franka); CCSu (Cabada Capa/SusPtrit); NuTr (Nure/Tremois). 


\section{QTL mapped at the adult plant stage.}

The recombinant inbred line (RIL) and doubled-haploid (DH) populations showed a continuous distribution for area under the disease-progress curve (AUDPC) or disease severity data collected from field experiments. Transgressive segregation was observed in four of five (StMo, no transgression) populations tested (Fig. 3). In total, 13 QTL for adult plant resistance were detected and these were distributed over all barley chromosomes (Fig. 2). Of the 13 QTL, 3 (Rbgq7, $R b g q 8$, and $R b g q 9$ ) were mapped in more than one population. Four QTL were detected in both developmental stages (Rbgq2a, Rbgq7, Rbgq9, and Rbgq13), of which two were detected in the VaSu population at seedling and adult plant stages. The phenotypic variation explained by the QTL ranged from 7.3 to $52.1 \%$, indicating great differences in the size of the effect of QTL on resistance at the adult plant stage. Four QTL (Rbgq12, Rbgq4, Rbgq7, and Rbgq8) were detected and confirmed in both years. The most consistent QTL were also the ones with the highest LOD scores. The inconsistent detection of the other QTL in different years may be due to limited power due to size of mapping populations, a high level of environment dependency or a different race composition of the pathogen population between years. Our results indicate that most QTL for powdery mildew resistance in barley are highly plant-developmental-stage dependent and that a high level of genetic diversity exists in barley for basal resistance to powdery mildew.

\section{Histology of resistance at the seedling stage.}

The reactions to Blumeria graminis f. sp. hordei $48 \mathrm{~h}$ after inoculation (hai) are presented for the parental lines and for the most resistant lines of each of the six studied mapping populations in Figure 4. At the macroscopic level, all parental lines, except L94, which carries the mlo gene, showed a compatible infection type (infection type 4). This implies that they do not carry an effective race-specific resistance $(R)$ gene against the Wag.04 isolate that was used. The proportion of failed infection units that were stopped at penetration stage in parental lines ranged from 20\% (OWBrec) to 63\% (SusPtrit) of attempted penetration sites. Invariantly, a higher proportion
OWB seedling stage

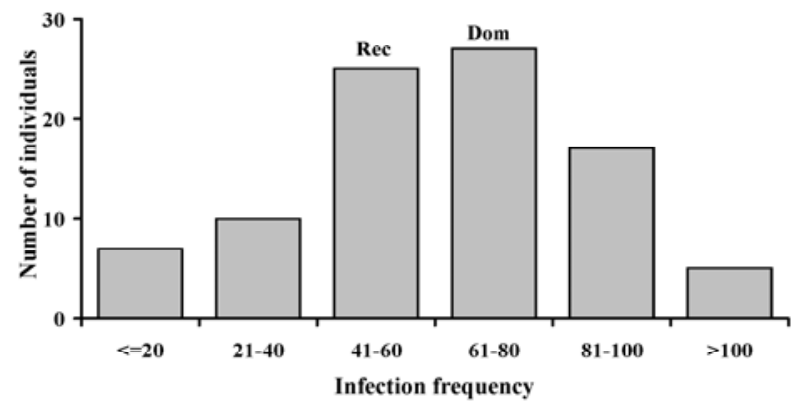

LnVa seedling stage

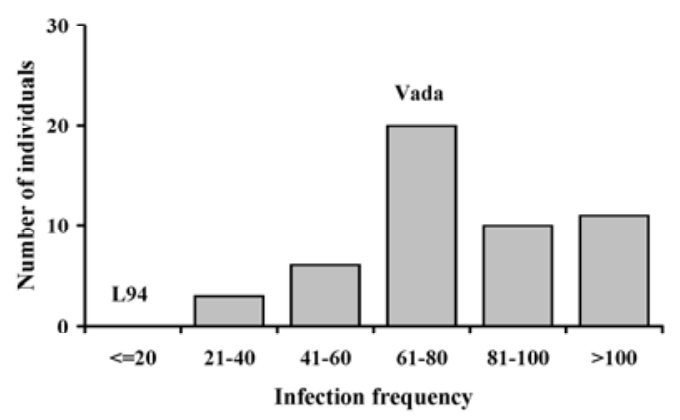

CCSu-seedling stage

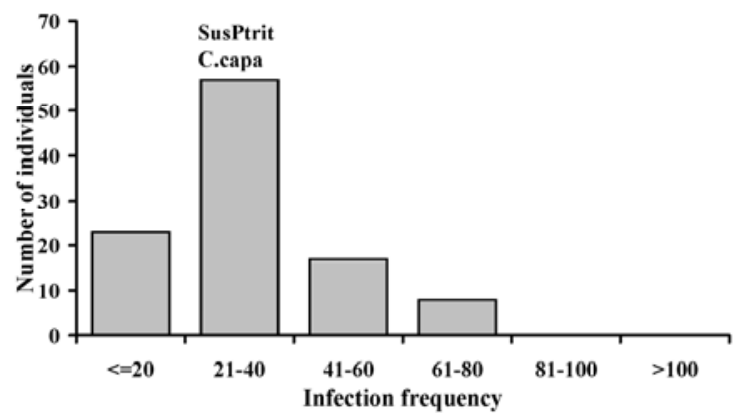

NuTr seedling stage

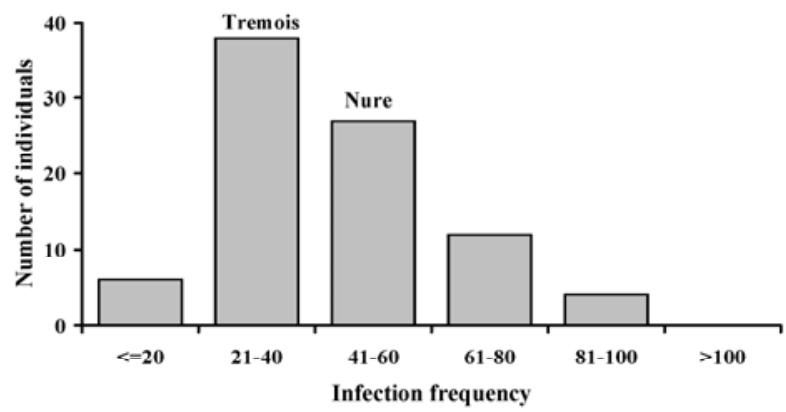

StMo seedling Stage

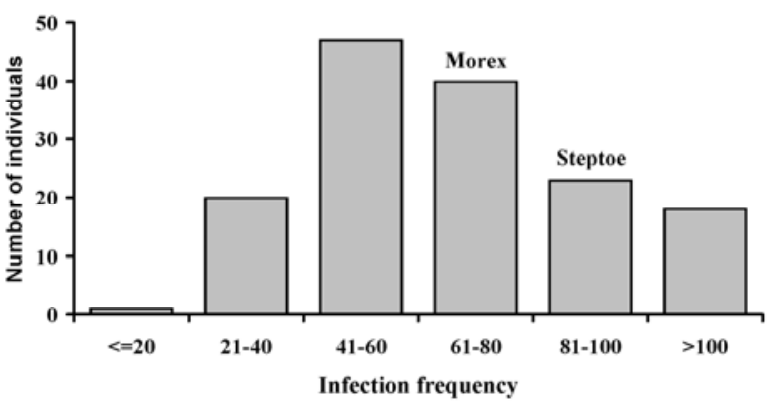

VaSu-seedling stage

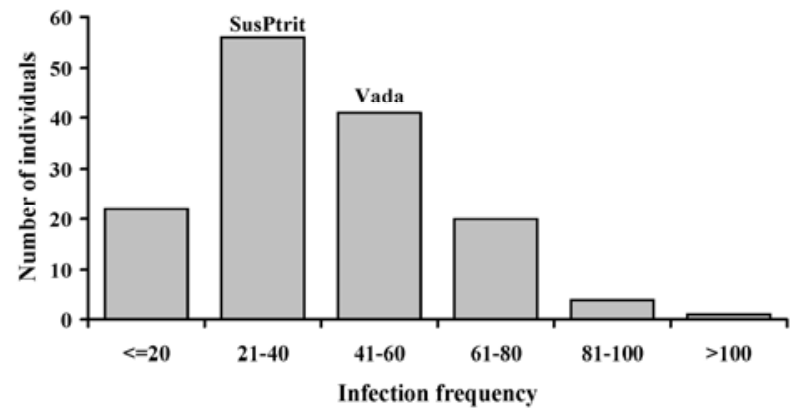

Fig. 1. Histograms of the frequency distribution of powdery mildew resistance phenotypes in six mapping populations of barley tested at the seedling stage. Infection frequency represents the number of colonies on $2 \mathrm{~cm}^{2}$ of infected leaf segments 4 days after inoculation. OWB = Oregon Wolfe Barley, NuTr $=$ Nure/Tremois, $\mathrm{CCSu}=\mathrm{Cebada} \mathrm{Capa} / \mathrm{SusPtrit}$, and $\mathrm{VaSu}=\mathrm{Vada} / \mathrm{SusPtrit}$. 
of infection units were stopped at the penetration stage in the most resistant lines rather than in the parents of the mapping populations. Apart from mlo resistance in L94, the highest proportion of papilla-associated aborted infection units (83\%) occurred in RIL 92 of the CCSu population. The proportion of penetrating infection units that were stopped in association with a hypersensitivity reaction of the challenged epidermal cells ranged from only $1 \%$ (OWBrec) to $11 \%$ (Vada) of the infection units. These results suggest that the QTL that were mapped at the seedling stage may determine papilla-associated nonhypersensitive, basal, or partial resistance.

\section{Candidate gene mapping.}

Of 38 EST-derived sequences representing candidate genes, 22 were mapped in at least one of the seven integrated mapping populations (Table 2; Supplementary Table S4). Seventeen candidate genes were converted to cleaved amplified polymorphic sequence (CAPS) markers. For one candidate gene, a single nucleotide polymorphism (SNP) was used to design a derived CAPS (dCAPS) marker using the dCAPS Finder online software. Two sequences were mapped as SCAR markers and two other sequences were previously mapped as RFLP markers. One sequence (clone ID: HO02M14) was polymorphic in the
$1 \mathrm{H}$

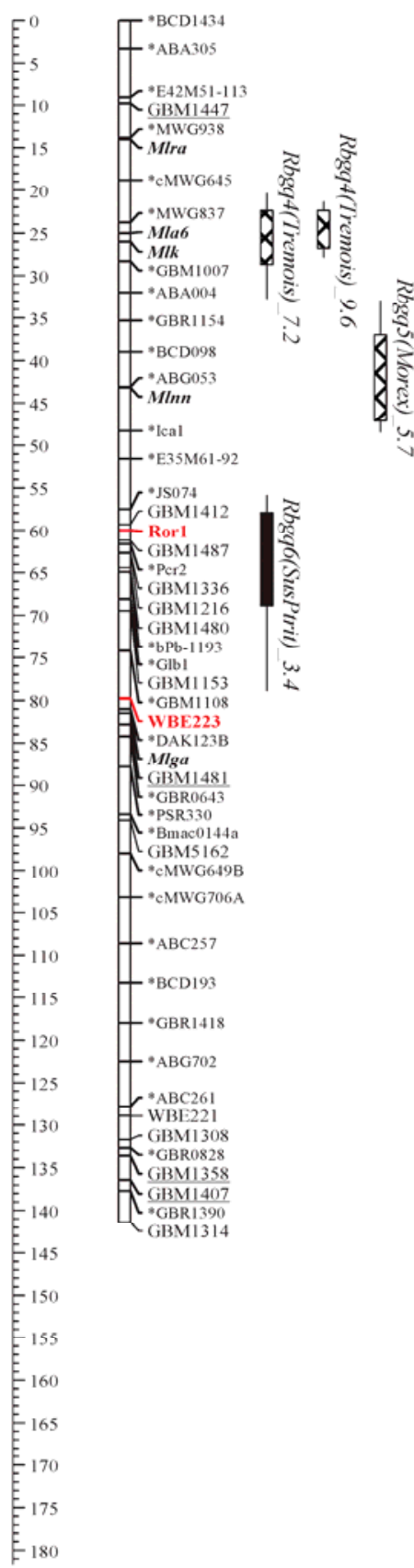

$2 \mathrm{H}$

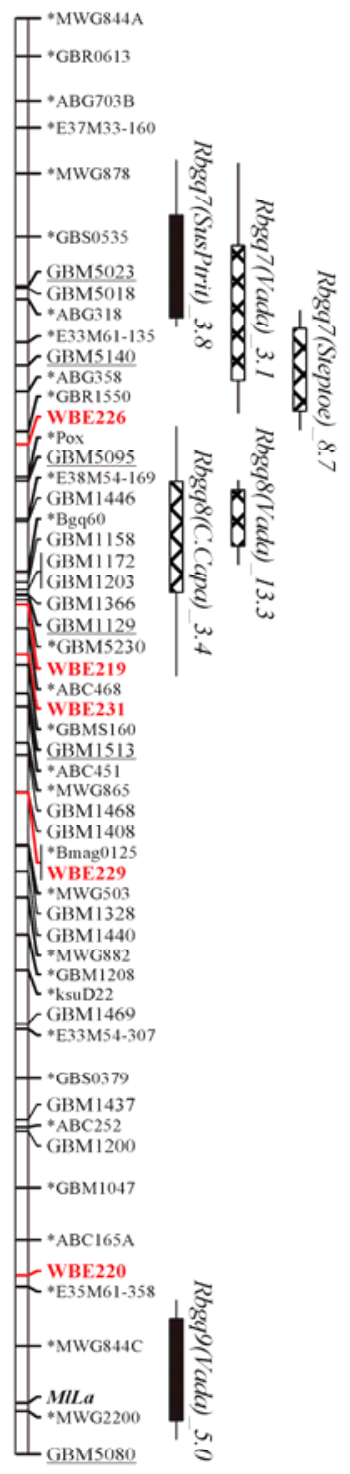

$3 \mathrm{H}$

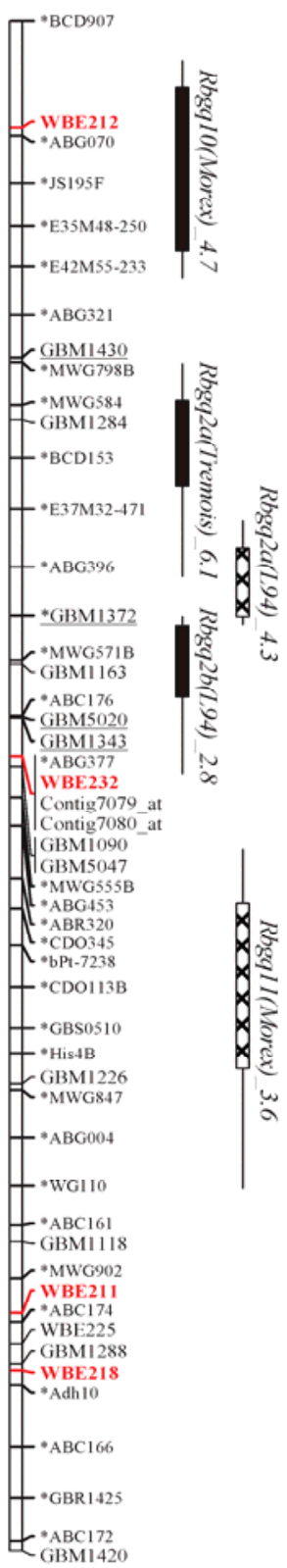

Continued on following page.

Fig. 2. Localization of candidate gene markers and quantitative trait loci (QTL) for resistance to powdery mildew on an integrated map of barley. Position of candidate genes, including mlo, Rorl, and Ror2, are in bold black. The locations of QTL are indicated by vertical bars at the right side of each linkage group. Solid bars represent QTL identified at the seedling stage under controlled conditions, and shaded bars represent QTL identified at the adult plant stage under field conditions. The length of QTL boxes represents approximately the log-likelihood ratio (LOD)-1 support interval and the length of QTL lines the LOD-2 support interval of the QTL based on r-multiple-QTL mapping results. 
CCSu population but could not be assigned to a map position with confidence. Fifteen candidate gene sequences remained for which no polymorphism was detected or for which it was not possible to obtain a clear polymerase chain reaction (PCR) amplification product in any of the parental combinations (clone ID: HO14H18, HO14K08, HO16C19, HO26F22, HO13M13, HZ40O15, HI05K17, HO15M05, HO13K06, HW03O11, HU02G09, AJ344223, AJ518932, AJ518933, and AM265370). The position of the mlo gene was determined directly in the LnVa map as being on chromosome 4H (Qi et al. 1998; Shtaya et al. 2006). Rorl is located within a $0.1 \mathrm{cM}$ distance of the ABG452 marker on chromosome 1H (Collins et al. 2001). Ror 2 is located on chromosome $5 \mathrm{H}$ based on its flanking markers as published by Collins and associates (2003).

\section{Co-localization between candidate genes and QTL.}

A $\chi^{2}$ test did not indicate a significant global co-localization between QTL and candidate genes $\left(\chi^{2}\right.$ value $\left.=0.79\right)$. Nevertheless, 6 of 25 mapped candidate genes showed coincidence in their map positions with the QTL identified for basal resis- tance to powdery mildew (Fig. 2; Table 2). We defined coincidence of a QTL and a candidate gene as when the candidate gene mapped within the LOD-1 interval of the QTL in our integrated map. In this article, we only discuss those candidate genes that are within $5 \mathrm{cM}$ from QTL peak markers because they are the most relevant ones. Despite similarities in the resistance mechanism between basal resistance and mlo-mediated resistance, none of the detected QTL showed coincidence with the map positions of mlo and the Ror 2 genes. The peak marker Rbgq6, a QTL mapped in the VaSu population at the seedling stage, is located within $0.1 \mathrm{cM}$ of ABG452, a marker closely linked to Rorl on chromosome $1 \mathrm{H}$. Shtaya and associates (2006) detected a QTL in the LnVa population (not detected in the present study) in the region where Ror 2 is located.

\section{Co-localizations between QTL and race-specific resistance genes.}

In most cases, the map positions of powdery mildew resistance QTL did not coincide with those of the race-specific $R$ genes. The $\chi^{2}$ test applied did not indicate a significant co-local-

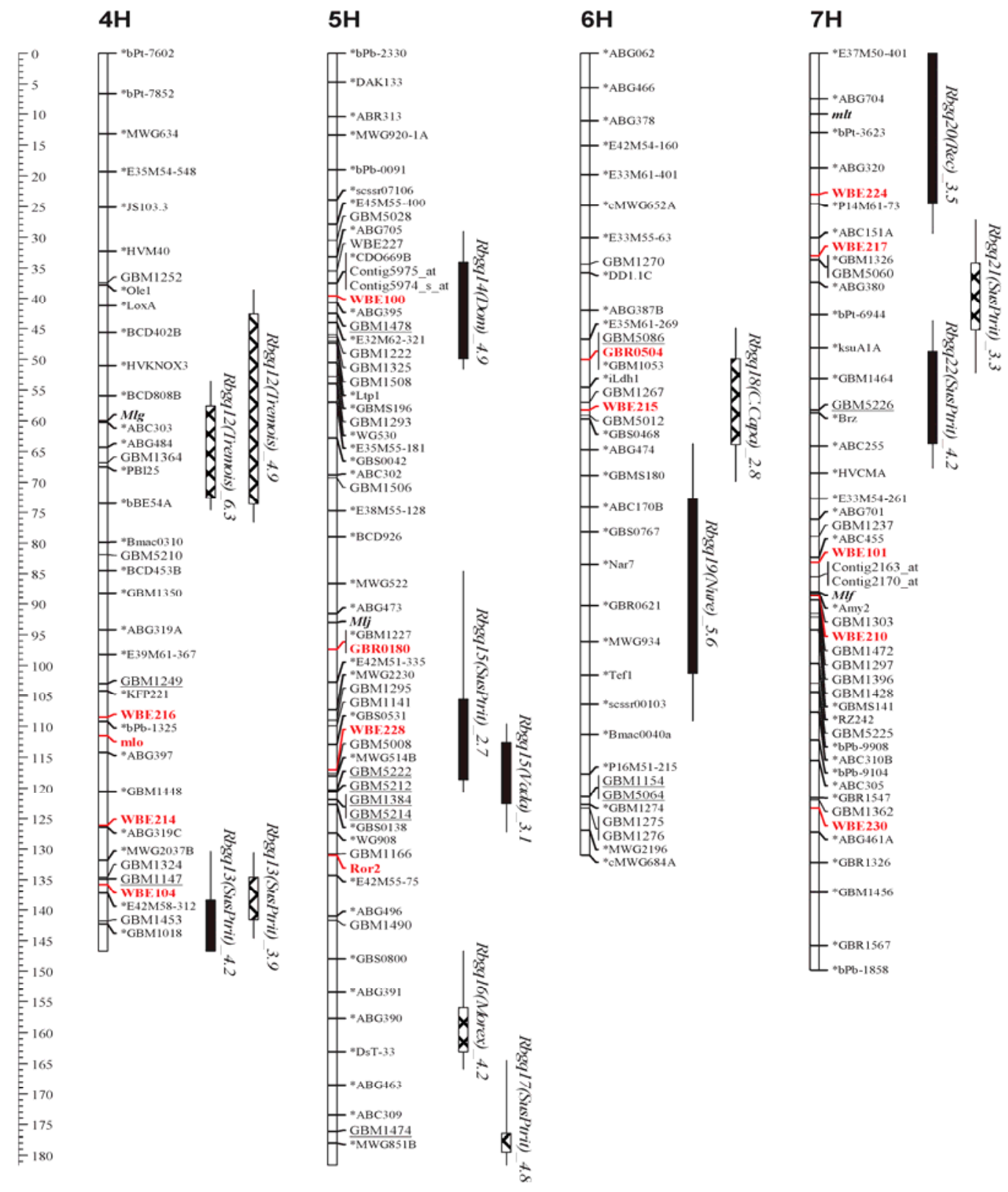

Fig. 2. Continued from previous page. 
ization between QTL and $R$ genes $\left(\chi^{2}=0.96\right)$. Only 5 of 21 QTL mapped in a region where an $R$ gene has been reported. We defined coincidence of a QTL and an $R$ gene as when the putative map position of the $R$ gene in our integrated map was located within the LOD-1 support interval of a QTL. Because the $R$ genes were mapped mostly in mapping populations that did not contribute to our integrated map, their map position in our integrated map is less precise than the map positions of the candidate gene-derived markers. A QTL mapped in the LnVa and VaSu populations $(\operatorname{Rbg} q 9)$ showed coincidence with the known map position of MlLa, a gene derived from Hordeum laevigatum and located on the long arm of chromosome $2 \mathrm{H}$. This gene causes an intermediate type of hypersensitive reaction to avirulent isolates (Giese et al. 1993; Marcel et al. 2007a). In both populations, the resistance QTL allele was contributed by Vada, a cultivar that carries the MlLa gene. Because the powdery mildew isolate used for evaluation of the populations at seedling stage was virulent to the MlLa gene, it is plausible that the explained phenotypic variation in this region is due to a QTL and not to MlLa itself. One QTL detected on chromosome 7H in the Oregon Wolfe Barley (OWB) (Rbgq20) showed coincidence with the map position of mlt. A QTL mapped on chromosome

VuTr Field 2006

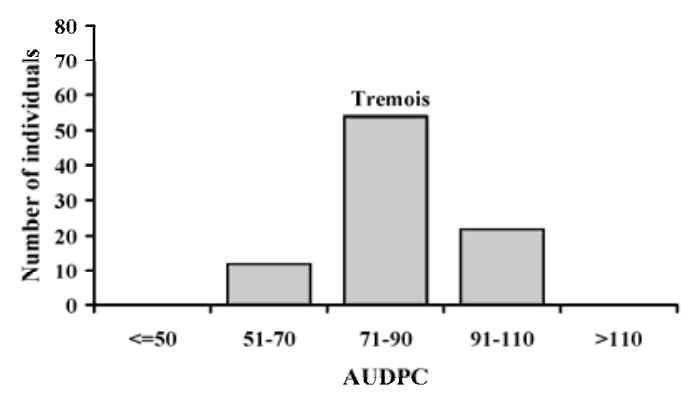

CCSu Field 2007

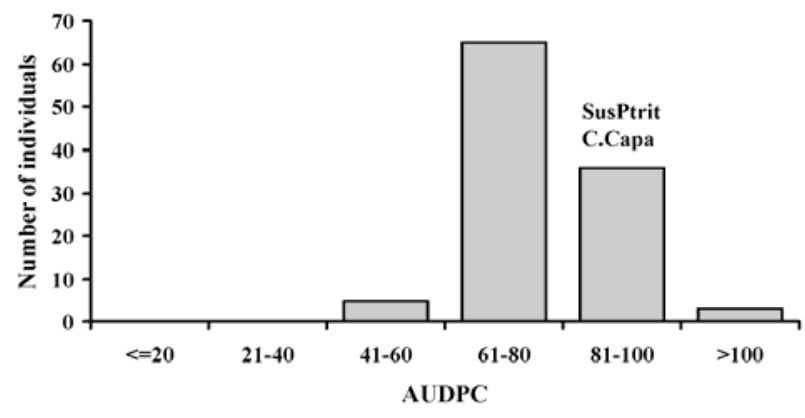

VaSu Field 2007

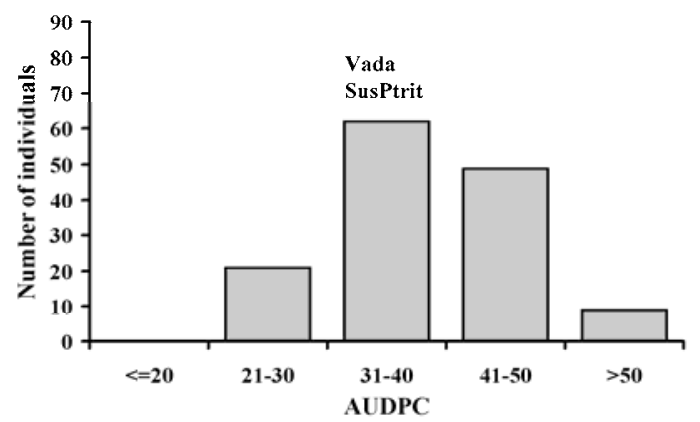

$1 \mathrm{H}$ in the Nure/Tremois (NuTr) population (Rbgq4) showed coincidence with the Mla and Mlk loci. Backes and associates (2003) also reported co-localization of QTL mapped in a cross between the barley $\mathrm{cv}$. Vada and a wild barley ( $H$. vulgare subsp. spontaneum line $1 \mathrm{~B}-87$ ) on chromosomes $1 \mathrm{H}$ and $7 \mathrm{H}$ with the Mla and Mlf loci, respectively. A QTL mapped in the StMo population (Rbgq5) on chromosome 1H showed coincidence with the map position of Mlnn. Finally, a QTL mapped in the $\mathrm{NuTr}$ population (Rbgq12) on chromosome $4 \mathrm{H}$ showed coincidence with the map position of $\mathrm{Mlg}$.

\section{DISCUSSION}

Diversity of QTL for powdery mildew resistance in barley.

Most mapping studies on quantitative, basal resistance of barley to powdery mildew have been based on individual populations. Here, we studied the genetic variation of basal resistance using multiple populations to assess also the diversity of the genes involved in the genetic variation. The QTL conferring basal resistance were distributed over all seven chromosomes of barley without obvious clustering. In different mapping populations, different sets of QTL were involved in basal resistance.
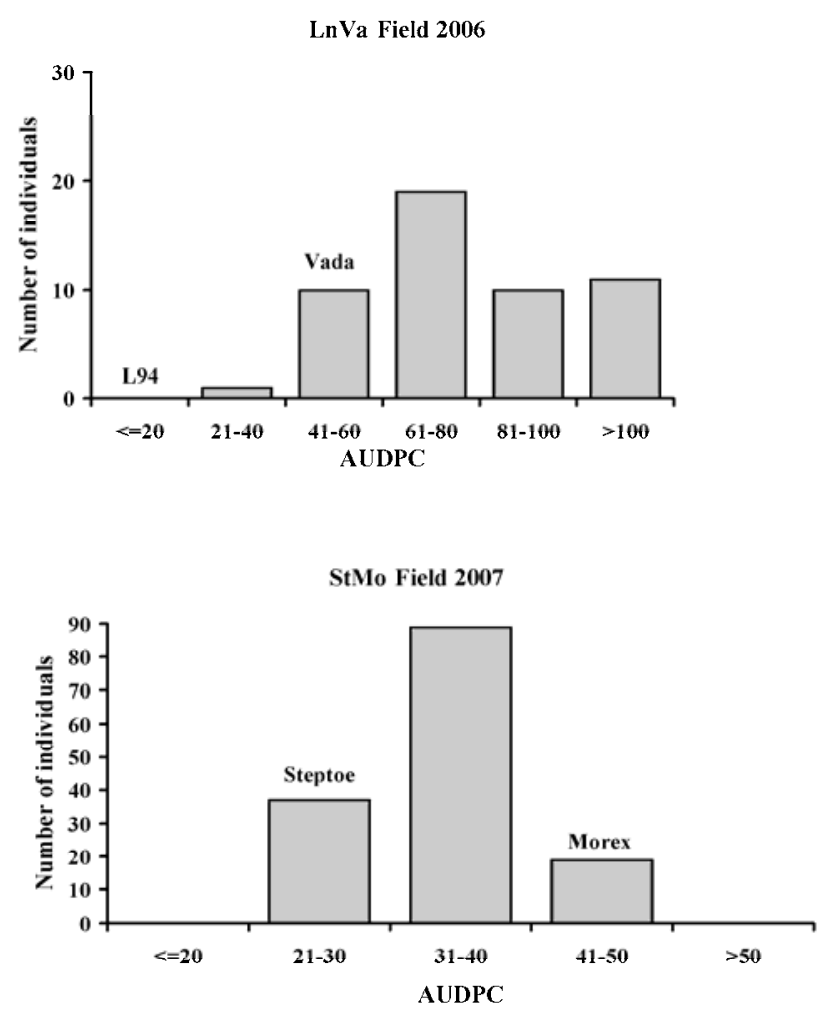

Fig. 3. Histograms of the frequency distribution of powdery mildew resistance phenotypes in five mapping populations of barley tested at the adult plant stage under field conditions. AUDPC $=$ area under the disease-progress curve. NuTr $=$ Nure/Tremois, LnVa $=$ L94/Vada, CCSu $=\mathrm{Cebada}$ Capa/SusPtrit, $\mathrm{StMo}=$ Steptoe/Morex, and $\mathrm{VaSu}=\mathrm{Vada} / \mathrm{SusPtrit}$. 
These indicated a great diversity for QTL (genes) for this trait in barley. A similar great diversity has been reported in genes conferring basal resistance in some other barley-pathogen interactions, such as barley-Puccinia hordei (Qi et al. 2000; Marcel et al. 2007b), barley-Rhynchosporium secalis (Zhan et al. 2008), barley-Fusarium spp. (Fusarium head blight [FHB]) (Mesfin et al. 2003; Sato et al. 2008), and barley-spot blotch (Bilgic et al. 2005). Marcel and associates (2007b) reported 19 QTL contributing to the basal resistance of barley to leaf rust in five mapping populations used to build the present barley integrated map. They showed that, in each barley mapping population, different sets of QTL segregate for basal resistance and only a few QTL were found in common in more than one barley cultivar. Similarly, QTL analyses for FHB resistance in different barley mapping populations indicated that the quantitative resistance of barley to FHB is conditioned by many loci (Mesfin et al. 2003). QTL for powdery mildew resistance have previously been reported in different mapping populations of barley (Heun 1992; Backes et al. 1995, 1996, 2003; Spaner et al. 1998; Falak et al. 1999; Read et al. 2003; Von Korff et al. 2005; Shtaya et al. 2006). We compared the position of the peak marker of the presently found QTL with the peak mark-

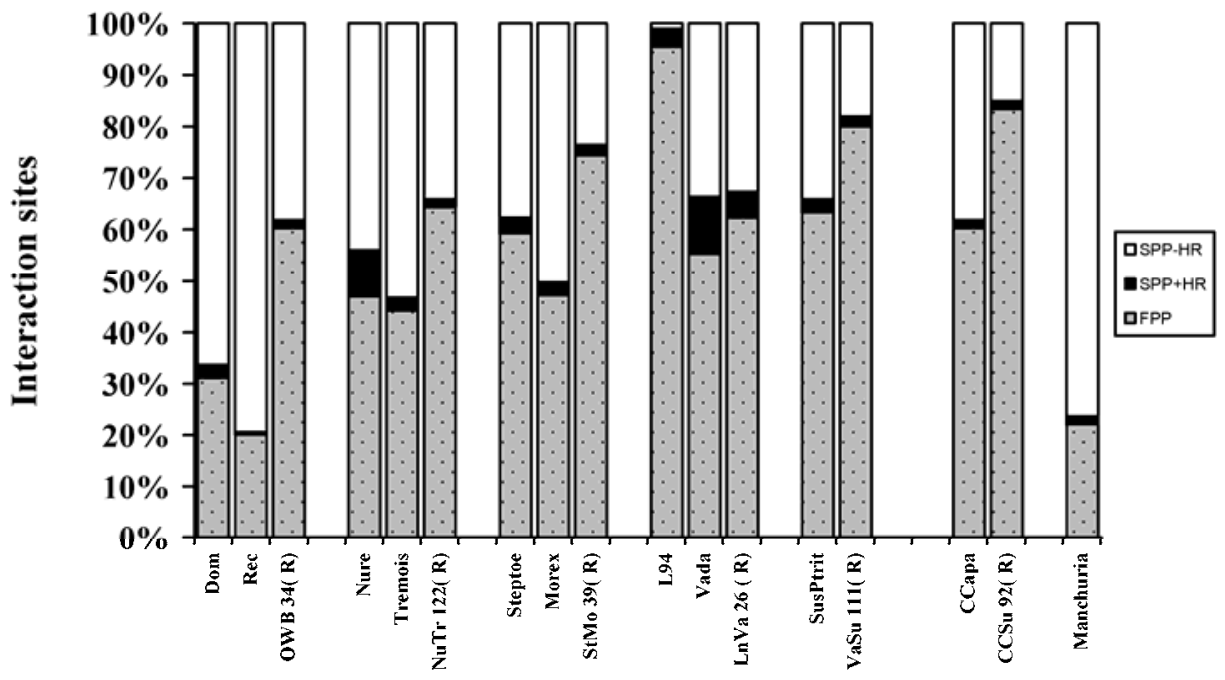

Fig. 4. Defense reaction of the parents and of the most resistant line of different mapping populations to Blumeria graminis f. sp. hordei at 48 h after inoculation. Data from each group represent the mean of two leaf segments; in each leaf, 100 infection sites have been evaluated. The dotted gray portions of columns represent failed primary penetration (FPP), when the fungus was stopped at the penetration stage; black sections represent successful primary penetration (SPP) resulting in a haustorium but with hypersensitive response (HR); and white sections represent SPP with haustorium and without HR. Lines with (R) represent the most resistant line from each mapping population.

Table 2. Characterization and map position of expressed sequence tags or cDNA clones representing candidate genes for powdery mildew resistance in barley

\begin{tabular}{|c|c|c|c|c|c|c|c|}
\hline $\begin{array}{l}\text { Clone } \\
\text { ID, acc. }\end{array}$ & Regul. ${ }^{a}$ & Effect $^{b}$ & Function & References & $\begin{array}{l}\text { Name of } \\
\text { marker }\end{array}$ & $\begin{array}{c}\text { Position } \\
\text { (chrom./cM) }^{\mathrm{c}}\end{array}$ & $\begin{array}{c}\text { Co-localization } \\
\text { with QTL }^{d}\end{array}$ \\
\hline HY05J20 & Up & Yes & Bax-inhibitor 1 & Hückelhoven et al. 2003 & GBR0504 & $6 \mathrm{H} / 51.6$ & $\cdots$ \\
\hline $\mathrm{HO} 08 \mathrm{H} 12$ & Up & Yes & HvGER4d & Zimmermann et al. 2006 & WBE104 & $4 \mathrm{H} / 135.8$ & Rbgq13 \\
\hline HW05P16 & Up & Yes & HvGER5a & Zimmermann et al. 2006 & GBR0180 & $5 \mathrm{H} / 97.4$ & $\ldots$ \\
\hline HO06J 21 & Up & n.a. & WIR1a & Schweizer et al.1999 & WBE101 & $7 \mathrm{H} / 83.1$ & $\ldots$ \\
\hline HO09K 14 & $\mathrm{Up}$ & n.a. & WIR $1 b$ & Zierold et al. 2005 & WBE100 & $5 \mathrm{H} / 35.5$ & $\ldots$ \\
\hline DQ647621 & Up & Yes & HvGER3a & Zimmermann et al. 2006 & WBE210 & $7 \mathrm{H} / 88.6$ & $\ldots$ \\
\hline HO02P09 & Up & n.a. & Unknown & Zierold et al. 2005 & WBE216 & $4 \mathrm{H} / 108.5$ & $\ldots$ \\
\hline HO07K06 & Up & n.a. & Unknown & Zierold et al. 2005 & WBE218 & $3 \mathrm{H} / 149.0$ & $\ldots$ \\
\hline HO11O12 & Up & n.a. & Unknown & Zierold et al. 2005 & WBE224 & $7 \mathrm{H} / 23.0$ & $\ldots$ \\
\hline HO13M20 & Up & n.a. & Unknown & Zierold et al. 2005 & WBE212 & $3 \mathrm{H} / 11.8$ & $\operatorname{Rbgq10}$ \\
\hline $\mathrm{HO} 14 \mathrm{~K} 22$ & Up & Yes & Receptor protein kinase-like & Zierold et al. 2005 & WBE211 & $3 \mathrm{H} / 142.7$ & $\ldots$ \\
\hline $\mathrm{HO} 14 \mathrm{P} 02$ & Up & n.a. & Receptor protein kinase-like & Zierold et al. 2005 & WBE220 & $2 \mathrm{H} / 136.2$ & $\ldots$ \\
\hline HO12E03 & Up & n.a. & Unknown & Zierold et al. 2005 & WBE217 & $7 \mathrm{H} / 33.0$ & $\ldots$ \\
\hline $\mathrm{HO} 07 \mathrm{H} 15$ & Up & n.a. & 4-Coumarate coenzyme A ligase & Zierold et al. 2005 & WBE215 & $6 \mathrm{H} / 59.8$ & $\operatorname{Rbgq18}$ \\
\hline HO40A01 & Up & n.a. & Hydrolase & Zierold et al. 2005 & WBE214 & $4 \mathrm{H} / 126.1$ & $\ldots$ \\
\hline HO12F09 & Up & Yes & SNAP-34 & $\begin{array}{l}\text { Douchkov et al. } 2005 \text {; } \\
\text { Jensen et al. } 2007\end{array}$ & WBE219 & $2 \mathrm{H} / 63.6$ & $\operatorname{Rbgq} 8$ \\
\hline HO06D23 & Up & Yes & P-type ATPase & Zierold et al. 2005 & WBE223 & $1 \mathrm{H} / 79.8$ & $\ldots$ \\
\hline HvPrx 40 & Up & Yes & Peroxidase & Johrde et al. 2008 & WBE232 & $3 \mathrm{H} / 81.2$ & $\ldots$ \\
\hline L37358 & $\mathrm{Up}^{\mathrm{e}}$ & n.a. & Lipoxygenase 2 & Bachmann et al. 2002, PLEXdb & WBE228 & $5 \mathrm{H} / 117.0$ & $\operatorname{Rbgq} 15$ \\
\hline Hv07A14 & $\mathrm{Up}^{\mathrm{e}}$ & n.a. & ACC synthase & PLEXdb & WBE229 & $2 \mathrm{H} / 83.9$ & $\ldots$ \\
\hline AJ536667 & Up & Yes & WRKY1 transcription factor & Eckey et al. 2004 & WBE230 & $7 \mathrm{H} / 123.3$ & $\ldots$ \\
\hline AJ534447 & $\mathrm{Up}^{\mathrm{e}}$ & n.a. & Apoplastic invertase & PLEXdb & WBE231 & $2 \mathrm{H} / 69.0$ & $\ldots$ \\
\hline
\end{tabular}

${ }^{a}$ Regulation in barley leaves inoculated with Blumeria graminis ff. spp.

${ }^{\mathrm{b}}$ RNA interference effect, the effect of transient-induced gene silencing of the test sequence on resistance in the single-cell system, or overexpression effect, the effect of single-cell transient overexpression of the test sequence on resistance in the single-cell system; n.a. = not analyzed.

c Chromosome (Chrom.) per centimorgan (cM).

${ }^{\mathrm{d}}$ Rbgq6, a quantitative trait locus (QTL) mapped in VaSu population at seedling stage, is co-localized with Ror1 on chromosome 1H.

${ }^{\mathrm{e}}$ Regulation by B. graminis f. sp. hordei or stem-rust inoculation in experiments BB2, BB4, BB7, or BB49 of Plant Expression Database (PLEXdb). Corresponding probe-set IDs: HV02H04, Contig12036_at; L37358, HI02E21u_s_at; HY07A14, Contig15618_at; AJ534447, Contig11241_at. 
ers of 28 reported QTL using our high-density integrated map of barley. In four cases (Rbgq2a, Rbgq4, Rbgq7, and Rbgq8), the location of the peak marker of QTL are only approximately 0 to $2 \mathrm{cM}$ away from previously reported QTL for mildew resistance and, in two cases (Rbgq2b and Rbgq14), the peak markers are 4 to $6 \mathrm{cM}$ away. One of these QTL (Rbgq4) has already been reported in two different populations of barley, Blenheim $\times$ E224 and Vada $\times$ 1B-87 (Thomas et al. 1995; Backes et al. 2003) (Supplementary Table S5). This suggests that, despite the great diversity of QTL for basal resistance to powdery mildew in barley, some QTL found in our study might be the same as QTL already reported in other genetic backgrounds. The genetic architecture of basal resistance against different fungal pathogens (e.g., P. hordei, FHB, and $B$. graminis) is similar (i.e., different sets of QTL in each mapping population with increasing overlap in detected QTL as the number of studied populations increases).

\section{Growth-stage specificity of QTL for basal resistance.}

Growth-stage-dependent and -independent resistance QTL have both been reported in many host-pathogen interactions, including powdery mildew (Backes et al. 2003) and leaf rust (Marcel et al. 2007b; Qi et al. 1999) in barley, Septoria leaf blotch in wheat (Eriksen et al. 2003), ascochyta blight in pea (Prioul et al. 2004), and downy mildew in lettuce (Zhang et al. 2009). In our study, only 4 out of a total of 21 QTL were detected at both growth stages (Rbgq2a, Rbgq7, Rbgq9, and Rbgq13), suggesting that QTL for powdery mildew resistance are mainly growth stage dependent. Similar results have been reported by Backes and associates (2003), who found that only one of five QTL that mapped in the Vada $\times 1 \mathrm{~B}-87$ population affected both growth stages measured. This is also in agreement with the report of Mastebroek and Balkema-Boomstra (1991), in which they concluded that the phenotypic expression of the basal resistance of barley to powdery mildew is growth stage dependent. Our histological observations confirm that the QTL mapped in the present work contribute mainly to a prehaustorial nonhypersensitive basal resistance rather than to an incomplete hypersensitive resistance.

\section{Co-localization of candidate genes and $\boldsymbol{R}$ genes with QTL regions.}

In field experiments under natural disease infection, an allelic difference for the presence versus absence of an $R$ gene, normally a qualitative effect, can behave similarly to a moderateeffect QTL. At least two reasons may account for this: i) the $R$ genes may have an intermediate effect (like $M l L a$ ) and ii) the natural population of the pathogen may consist of a mixture of virulent and avirulent races to a certain $R$ gene, resulting in a lower epidemic mildew development in genotypes carrying the $R$ gene than in genotypes carrying the susceptibility allele (Parlevliet 1983; Parlevliet and van Ommeren 1985). Furthermore, QTL that co-localize with $R$ genes for resistance may be allelic variants of $R$ genes or the residual effect of defeated $R$ genes (Kelly and Vallejo 2005; Niks and Marcel 2009). Even if, in our study, $50 \%$ of the 10 mapped $R$ genes co-localized with QTL for mildew resistance, this association was not significant according to the $\chi^{2}$ test.

The molecular basis of quantitative (basal) resistance, like other genetically complex traits, is poorly understood. Candidate gene analysis can be considered an important approach toward understanding the molecular basis of quantitative resistance, partly thanks to the availability of huge numbers of EST in databases. The high diversity of QTL implicated in the level of basal resistance of a plant species against a specific fungal pathogen makes it easy to identify co-localizations with candidate genes but more difficult to identify the relevant ones. Thus, a prioritization approach is necessary. In the present study, we found co-localizations of QTL for resistance with genes that have been suggested by reverse genetics to be involved in the barley-powdery mildew interaction. Of 25 mapped candidate genes, six showed coincidence with the position of QTL for powdery mildew resistance (Fig. 2; Table 2). The co-localization of some candidate-based markers with peak markers of QTL in rather small populations (in this study, LnVa, OWB, and NuTr RIL or DH populations) certainly requires verification, preferably by fine mapping in QTL near-isogenic lines. The inaccuracy due to limited population size may have resulted in either larger or smaller distances between the QTL and the candidate gene marker than exist in reality. Therefore, we used an arbitrary distance of $5 \mathrm{cM}$ as threshold to consider the peak and candidate markers as potentially co-localizing.

TIGS experiments showed that a t-SNARE protein, HvSNAP34, is involved in three types of durable, non-racespecific resistances, namely mlo-mediated, nonhost, and host basal resistance (Douchkov et al. 2005). Map co-localization of HvSNAP34 with a QTL (Rbgq8) for powdery mildew resistance on chromosome $2 \mathrm{H}$ provides further evidence for the role of this gene in basal resistance. Another QTL (Rbgq7) colocalized with the known map position of Rorl on chromosome $1 \mathrm{H}$. In the present study, we could not confirm a QTL against powdery mildew to be located near the Ror2 locus, as reported by Shtaya and associates (2006). Their data also suggest that an allelic form of Ror 2 may contribute to the increased basal resistance powdery mildew. A candidate gene that co-localized with the Rbgq13 on chromosome $4 \mathrm{H}$ is HvGER4d, a member of the multigene family of Germin-like proteins. HvGER4d is reported to encode enzymes with superoxide dismutase activity that are involved in local accumulation of hydrogen peroxide, a known signaling molecule for plant defense reactions (Zimmermann et al. 2006). Recently, a similar sequence, OsGER4, in rice (Oryza sativa) was reported to be involved in basal resistance against two different fungal pathogens. Suppression of OsGER4 increased the susceptibility of rice plants to the fungal pathogens causing blast and sheath blight diseases (Manosalva et al. 2009). Another QTL, Rbgq18, on chromosome $6 \mathrm{H}$, co-localized with a candidate gene that encodes 4-Coumarate coenzyme A ligase, which is an important enzyme involved in biosynthesis of phenolic compounds, lignin, and phytoalexins (Vidhyasekaran 2003).

Map co-localization between resistance gene analogs and defense-related genes with QTL for seedling or adult plant resistance have been reported in many other host-pathogen systems (Faris et al. 1999; Pflieger et al. 1999; Geffroy et al. 2000; Wang et al. 2001; Prioul-Gervais et al. 2007; Marcel et al. 2007b). $\mathrm{Hu}$ and associates (2008) established a candidate gene strategy that integrates linkage map, expression profile, and functional complementation analyses with the purpose of cloning QTL that are responsible for the quantitative resistance of rice to bacterial blight and fungal blast. However, using more than one mapping population provides an insight into the diversity of the genes responsible for basal resistance. With a larger number of mapping populations available and more QTL detected, it is possible to test a larger sample of QTL for their statistical coincidence with candidate genes. The use of an integrated map to compare data obtained from different populations also increases the chance of discovering relevant co-localizations. Here, we prioritized the candidate genes by accumulating evidence for position, biological function, and functional proof by TIGS. However, map co-localization of candidate genes with the QTL involved in the trait variation is not sufficient proof of a causal relationship, and actual involvement of the candidate genes in the trait variation should be validated by either positional cloning, genetic complementa- 
tion tests using mutants or transformants, or appropriate biochemical and physiological analyses (Pflieger et al. 2001). The integrated candidate gene strategy has proven to be a fast and efficient approach for the isolation of genes with small effects (Hu et al. 2008). Information gained from this approach may help breeders to use the valuable sources of diversity more efficiently to improve the level of basal resistance in crop plants.

\section{MATERIALS AND METHODS}

\section{Marker data sets.}

Segregating marker data from seven individual mapping populations were compiled to prepare a high-density genetic integrated map of barley. The populations consisted of four DH populations: Igri/Franka (IgFr, 71 lines) (Graner et al. 1991), StMo (150 lines) (Kleinhofs et al. 1993), the OWB (94 lines) (Costa et al. 2001), and NuTr (118 lines) (Francia et al. 2004); and three RIL populations: LnVa (103 lines) (Qi et al. 1998), VaSu (152 lines) (Jafary et al. 2006), and CCSu (113 lines) (Jafary et al. 2008).

We reused the data sets compiled by Marcel and associates (2007b) after excluding the AFLP markers mapped on the OWB. We added the DArT and TDM marker data sets released by Wenzl and associates (2006) and Potokina and associates (2008) (StMo), respectively; the SSR and EST marker data sets released by Varshney and associates (2007) and Stein and associates (2007) (IgFr, StMo, and OWB), respectively; and new marker data posted on the Oregon State University Barley Project web site (OWB). The marker data set of NuTr consisted of 542 markers, mostly DArT markers (72\%), and was obtained from N. Pecchioni (Università di Modena e Reggio Emilia, Italy). Segregation of the data from most of the BIN markers defined by Kleinhofs and Graner (2001) (StMo) was obtained from A. Kleinhofs (Washington State University).

Three new marker data sets were also included in the present integrated map and consist of 168 "PERO" markers mapped in LnVa and VaSu by peroxidase-profiling (to be published elsewhere by our laboratory), 26 new EST-SSR markers mapped in $\mathrm{NuTr}$ or CCSu by A/T labeling (Marcel et al. 2007b) (Supplementary Table S1), and the 22 candidate genes described in the present study (Table 2).

\section{Construction of the barley integrated map.}

The integrated map was constructed essentially as described by Marcel and associates (2007b) using the software JoinMap 4 and MapChart (Voorrips 2002). All the bridge markers (i.e., markers common to two or more populations), the $210 \mathrm{BIN}$ markers defined by Marcel and associates (2007b), and the additional BIN markers provided by A. Kleinhofs were used to prepare the framework map. The order of the 210 BIN markers was initially used as a fixed order to run the regression mapping algorithm. After each mapping, the obtained marker order was compared with the marker order from the integrated map of Marcel and associates (2007b). Most discrepancies between the two marker orders were investigated by graphical genotyping in order to reject or to validate the newly calculated map. In cases where the newly calculated map was rejected, the fixed order was modified and the mapping repeated until the discrepancy was corrected. Consequently, in cases where the new map was validated, it could only represent an improvement from the previous integrated map of Marcel and associates (2007b). Then, the marker order on the constructed framework map was used as a fixed order to run the maximum likelihood mapping algorithm on the 49 linkage groups (i.e., seven barley chromosomes for seven mapping populations); default values were increased to five map optimization rounds with 3,000 chains. Three maps were generated for each linkage group and aligned to compare the order and distances between markers. From each alignment or linkage group, the map showing the most consistent marker order and the shortest total length was integrated into the framework map following the "neighbors" approach. The obtained integrated map was divided into 217 BIN markers of approximately $5 \mathrm{cM}$ each. The BIN-defining markers of Kleinhofs and Graner (2001) were maintained in their role whereas the BIN-defining markers of Marcel and associates $(2007 \mathrm{~b})$ were sometimes modified to obtain a more homogeneous distribution of BIN markers over the map.

\section{Plant and pathogen materials.}

Six of seven (IgFr excluded) mapping populations were evaluated for their level of basal resistance to barley powdery mildew at the seedling stage under controlled conditions, and five populations (IgFr and OWB excluded) were evaluated at the adult plant stage under field conditions. An isolate of $B$. graminis f. sp. hordei collected in Wageningen 2004 (Wag.04) was used for evaluation of resistance levels at the seedling stage. This isolate was maintained in a climate cabinet and propagated on young seedlings of the susceptible barley cv. Manchuria.

\section{Assessment of resistance level at the seedling stage.}

Evaluation of powdery mildew resistance at the seedling stage was performed on detached leaves. Barley plants were grown in spore-free greenhouse compartments. Twelve days after sowing, when the first leaf was fully expanded, a 4-cmlong segment was cut from the middle part of the first leaves and placed in a square $(12$ by $12 \mathrm{~cm})$ polystyrene petri dish, the adaxial side of the leaf facing upwards, by embedding both extremities of the leaf segments in $0.6 \%$ water agar containing benzimidazole at $125 \mathrm{ppm}$. Each petri dish accommodated approximately 16 leaf segments. One leaf segment was taken per RIL or DH line per experiment. Both parents of each mapping population and the susceptible cv. Manchuria were added to each petri dish as reference. To use freshly produced conidia for inoculation, young seedlings of the susceptible cv. Manchuria were densely inoculated with powdery mildew 7 days before inoculation. Per inoculation, four petri dishes containing the leaf segments were put inside a settling tower. Conidia from heavily infected leaves were blown into the tower using compressed air and were allowed to settle for $10 \mathrm{~min}$. The density of the inoculum was monitored with a hemocytometer and adjusted to 10 to $15 \mathrm{conidia} / \mathrm{mm}^{2}$. Following inoculation, the closed petri dishes were incubated in a growth chamber at $20^{\circ} \mathrm{C}$ with fluorescent light irradiance $\left(102.8 \mu \mathrm{mol} / \mathrm{m}^{2} / \mathrm{s}\right)$ supplied for $12 \mathrm{~h}$ per day. After 4 days of incubation, symptoms were scored by counting the number of young powdery mildew colonies per $2 \mathrm{~cm}^{2}$ of leaf segment, using a magnifying glass $(\times 10)$. The experiment was repeated three times and the average infection frequency was used for QTL analysis. Because L94 is an mlo-barley, it is fully resistant to powdery mildew. Thus, in our inoculation experiments, we only included non-mlo-carrying RIL (51 accessions) of the LnVa population (Shtaya et al. 2006).

\section{Histology of infection by powdery mildew.}

To determine the mechanism of resistance at the cellular level, one DH line or RIL from each mapping population selected for its high level of basal resistance at the seedling stage together with the parental lines were selected for microscopic observations. The susceptible barley cv. Manchuria was included as reference. From each accession, two seedlings were grown in boxes ( 37 by $39 \mathrm{~cm}$ ). Twelve days after sowing, the first formed leaves were fixed in horizontal position, with the adaxial side up. The inoculation was performed using the set- 
tling tower with freshly produced spores collected from young susceptible barley plants. The inoculum density was adjusted to 10 to 15 conidia $/ \mathrm{mm}^{2}$. In each inoculation, one seedling from each accession was sampled for histological analysis and the other one was kept to check the efficiency of inoculation. The experiment was performed in two replications. At 48 hai, a leaf segment from the inoculated leaves was cut and transferred to a solution of 3,3'-diaminobenzidine at $1 \mathrm{mg} \mathrm{ml}^{-1}$ for $8 \mathrm{~h}$ and, subsequently, to a solution of acetic acid-ethanol $(3: 1$, $\mathrm{vol} / \mathrm{vol}$ ) to be cleared overnight. The leaf segments were stained with $0.005 \%$ Trypan Blue as described by Anker and Niks (2001). To make the preparations, the leaf segments were embedded adaxial side up in glycerol. Leaf segments were examined at $\times 400$ magnification using an Axiophot microscope (Zeiss, Oberkochen, Germany). In all microscopic observations, only interstomatal (type B epidermal cells, following the terminology proposed by Koga and associates [1990]) were examined. Those germlings that were stopped in association with papilla formation at the penetration stage were considered to be failed primary penetration and germlings that formed a haustorium and elongated secondary hyphae were considered to be successful primary penetration (Asher and Thomas 1983). Those epidermal cells that were challenged by more than one conidium were not considered.

\section{Phenotypic assessment at the adult plant stage.}

Evaluation of basal resistance at the adult plant stage was carried out under field conditions with naturally occurring powdery mildew infections. The parents and lines of different mapping populations were sown in three replications according to a randomized complete block design in spring 2006 and 2007. Each genotype was sown in three-row plots that were 1 $\mathrm{m}$ long with $25-\mathrm{cm}$ row distances. To minimize the effect of interplot interference (Parlevliet and Van Ommeren 1984; Lipps and Madden 1992), barley plots were alternated with three-row plots of nonhost oat. The plots were treated following standard agricultural practices. Mildew severity was recorded two or three times at 8- to 10-day intervals according to the 0 -to- 9 scale $(0=$ no infection and $9=$ fully covered by mildew) of Saari and Prescott (1975). The AUDPC was calculated (Jeger and Viljanen-Rollinson 2001) and used as the quantitative trait for QTL analysis. For the CCSu population in the 2006 field test, the disease severity was recorded only once and directly used for QTL analysis. For NuTr, the data were collected from 2-by-3-m yield trial plots of 88 spring type lines during the spring of 2005 and 2006, without alternating oat plots. The possible effects of interplot interference were minimized by sampling only the middle rows of the plots.

\section{QTL analysis.}

The quantitative resistance data were combined with the already available skeletal marker map data and analyzed with the software package MapQTL, version 5 (Van Ooijen 2004). First an interval mapping analysis was performed. Markers with the highest LOD values (above the threshold of 3 ) were selected as the initial set of possible co-factors for multipleQTL mapping analysis (Jansen 1993; Jansen and Stam 1994). The LOD threshold for detecting QTL was calculated by a permutation test with 10,000 iterations and a significance level $\alpha$ $=0.05$. A threshold LOD value above or equal to the LOD value suggested by the permutation test was used to declare the presence of a QTL. Positions of the detected QTL were determined on the individual maps and then extrapolated to the barley integrated map. QTL were named " $R b g q$ " (reaction to B. graminis, quantitative) followed by the QTL number as suggested by Shtaya and associates (2006). A common name was given to QTL for which the LOD-1 interval was overlapping.

\section{Mapping candidate genes and their co-localization} with QTL.

In all, 33 EST-derived sequences were provided by $\mathrm{P}$. Schweizer (The Leibniz Institute of Plant Genetics and Crop Plant Research, IPK, Germany) and five sequences were provided by R. Hückelhoven (Technical University of Munich, Germany). These EST represent candidate genes implicated in basal resistance, because they promoted or decreased haustorium formation by $B$. graminis upon RNAi silencing or overexpression. SNP or haplotypes of several of the candidates were significantly associated with powdery mildew resistance (A. Johrde and P. Schweizer, unpublished data). We tried to convert those sequences to polymorphic PCR markers to map them on one of the barley mapping populations used to construct the integrated map. Primer pairs were designed using the DNASTAR software package based on the full-coding-sequence when available or using genomic or cDNA sequences present in public databases (CR-EST: The IPK Crop EST Database, The National Center for Biotechnology Information [NCBI], and The TIGR Gene Index at DFCI). EST sequences were converted to CAPS, dCAPS, or SCAR markers to be mapped on one of the four mapping populations: CCSu, OWB, StMo, and LnVa. The candidate gene based markers were placed on the integrated map of barley to be compared with the position of QTL for resistance to powdery mildew. We considered $m l o$ and the two genes that are required for $\mathrm{mlo}$ mediated resistance, Rorl and Ror2, to be candidate genes to compare their map positions with QTL. The mlo gene was already mapped in the LnVa population (Qi et al. 1998). We located the Ror genes on the map based on the position of reported co-segregating markers (Collins et al. 2001, 2003). To determine the global significance of co-localizations between QTL and candidate genes, a $\chi^{2}$ test was performed. The null hypothesis of independent distribution of 5-cM BIN markers containing a QTL peak marker and BIN markers containing a candidate gene was tested.

\section{Comparing the map position of QTL with known $R$ genes.}

The Mla6 and MlLa genes were already located on the integrated map based on marker data from the $\mathrm{IgFr}$ and LnVa populations. Other $R$ genes (Mlra, Mlk, Mlnn, Mlga, Mlg, Mlj, $M l t$, and $M l f$ ) were located on the map based on the reported position of co-segregating markers (Schonfeld et al. 1996; Kurth et al. 2001; Jahoor et al. 2004).

\section{ACKNOWLEDGMENTS}

R. Aghnoum was supported by the Agricultural Research and Education Organization (AREO) and the Ministry of Science Research and Technology of Iran. We thank A. Vels for excellent technical assistance in greenhouse and field experiments; R. Hückelhoven (Technical University of Munich, Germany) for sharing five sequences of candidate genes; C. Boyd and A. Kleinhofs from Washington State University for making the segregation data of many BIN markers available; F. van Eeuwijk and the INCOA3 Project MABDE No. ICA3-2002-10073 for allowing us to collect powdery mildew data from the field experiments of the NuTr population; R. K. Varshney from ICRISAT for providing primer aliquots and marker information for the new set of EST-SSR markers; IPK in Germany for developing those EST-SSR markers; M.-A. Bonvoisin from ESITPA in France for his hard work mapping this new set of EST-SSR markers; and R. Visser for critical reading of the manuscript. T. C. Marcel was supported by the BIOEXPLOIT EU Integrated Project FOOD-CT-2005-513959.

\section{LITERATURE CITED}

Anker, C. C., and Niks, R. E. 2001. Prehaustorial resistance to the wheat leaf rust fungus, Puccinia triticina, in Triticum monococcum (s.s.). Euphytica 117:209-215.

Asher, M. J. C., and Thomas, C. E. 1983. The expression of partial resistance to Erysiphe graminis in spring barley. Plant Pathol. 32:79-89. 
Bachmann, A., Hause, B., Maucher, H., Garbe, E., Vörös, K., Weichert, H., Wasternack, C., and Feussner, I. 2002. Jasmonate-induced lipid peroxidation in barley leaves initiated by distinct 13-LOX forms of chloroplasts. Biol. Chem. 383:1645-1657.

Backes, G., Graner, A., Foroughi-Wehr, B., Fischbeck, G., Wenzel, G., and Jahoor, A. 1995. Localization of quantitative trait loci (QTL) for agronomic important characters by the use of a RFLP map in barley (Hordeum vulgare L.). Theor. Appl. Genet. 90:294-302.

Backes, G., Schwarz, G., Wenzel, G., and Jahoor, A. 1996. Comparison between QTL analyses on powdery mildew resistance in barley based on detached primary leaves and on field data. Plant Breed. 115:419421

Backes, G., Madsen, L. H., Jaiser, H., Stougaard, J., Herz, M., Mohler, V., and Jahoor, A. 2003. Localization of genes for resistance against Blumeria graminis f. sp. hordei and Puccinia graminis in a cross between a barley cultivar and a wild barley (Hordeum vulgare ssp spontaneum) line. Theor. Appl. Genet. 106:353-362.

Bilgic, H., Steffenson, B. J., and Hayes, P. M. 2005. Comprehensive genetic analyses reveal differential expression of spot blotch resistance in four populations of barley. Theor. Appl. Genet. 111:1238-1250.

Collins, N. C., Lahaye, T., Peterhänsel, C., Freialdenhoven, A., Corbitt, M., and Schulze-Lefert, P. 2001. Sequence haplotypes revealed by sequence-tagged site fine mapping of the Rorl gene in the centromeric region of barley Chromosome 1H. Plant Physiol. 125:1236-1247.

Collins, N. C., Thordal-Christensen, H., Lipka, V., Bau, S., Kombrink, E., Qiu, J. L., Hückelhoven, R., Stein, M., Freialdenhoven, A., Somerville, S. C., and Schulze-Lefert, P. 2003. SNARE-protein-mediated disease resistance at the plant cell wall. Nature 425:973-977.

Costa, J. M., Corey A., Hayes, P. M., Jobet, C., Kleinhofs, A., KopischObusch, A., Kramer, S. F., Kudrna, D., Li, M., Riera-Lizarazu, O., Sato, K., Szucs, P., Toojinda, T., Vales, M. I., and Wolfe, R. I. 2001. Molecular mapping of the Oregon Wolfe Barleys: A phenotypically polymorphic doubled-haploid population. Theor. Appl. Genet. 103:415-424.

Dong, W. B., Nowara, D., and Schweizer, P. 2006. Protein polyubiquitination plays a role in basal host resistance of barley. Plant Cell 18:33213331.

Douchkov, D., Nowara, D., Zierold, U., and Schweizer, P. 2005. A highthroughput gene-silencing system for the functional assessment of defense-related genes in barley epidermal cells. Mol. Plant-Microbe Interact. 18:755-761

Eckey, C., Korell, M., Leib, K., Biedenkopf, D., Jansen, C., Langen, G., and Kogel, K. H. 2004. Identification of powdery mildew-induced barley genes by cDNA-AFLP: Functional assessment of an early expressed MAP kinase. Plant Mol. Biol. 55:1-15.

Eriksen, L., Borum, F., and Jahoor, A. 2003. Inheritance and location of resistance to Mycosphaerella graminicola causing Septoria tritici blotch and plant height in the wheat (Triticum aestivum L.) genome with DNA markers. Theor. Appl. Genet. 107:515-527.

Falak, I., Falk, D. E., Tinker, N. A., and Mather, D. E. 1999. Resistance to powdery mildew in a doubled haploid barley population and association with marker loci. Euphytica 107:185-192.

Faris, J. D., Li, W., Gill, B. S., Liu, D., and Chen, P. 1999. Candidate gene analysis of quantitative disease resistance in wheat. Theor. Appl. Genet. 98:219-225

Francia, E., Rizza, F., Cattivelli, L., Stanca, AM., Galiba, G., Tóth, B., Hayes, P. M., Skinner, J. S., and Pecchioni, N. 2004. Two loci on Chromosome $5 \mathrm{H}$ determine low-temperature tolerance in a 'Nure' (winter) $\times$ 'Tremois' (spring) barley map. Theor. Appl. Genet. 108:670-680.

Freialdenhoven, A., Peterhänsel, C., Kurth, J., Kreuzaler, F., and SchulzeLefert, P. 1996. Identification of genes required for the function of nonrace specific mlo resistance to powdery mildew in barley. Plant Cell 8:5-14.

Geffroy, V., Sevignac, M., De Oliveira, J. C. F., Fouilloux, G., Skroch, P., Thoquet, P., Gepts, P., Langin, T., and Dron, M. 2000. Inheritance of partial resistance against Colletotrichum lindemuthianum in Phaseolus vulgaris and co-localization of quantitative trait loci with genes involved in specific resistance. Mol. Plant-Microbe Interact. 13:287-296.

Giese, H., Holm-Jensen, A. G., Jensen, H. P., and Jensen, J. 1993. Localization of the Laevigatum powdery mildew resistance to barley Chromosome 2 by the use of RFLP markers. Theor. Appl. Genet. 85:897900

Graner, A., Jahoor, A., Schondelmaier, J., Siedler, H., Pillen, K., Fischbeck, G., Wenzel, G., and Herrmann, R. G. 1991. Construction of an RFLP map of barley. Theor. Appl. Genet. 83:250-256.

Heun, M. 1992. Mapping quantitative powdery mildew resistance of barley using a restriction fragment-length polymorphism map. Genome 35:10191025

Hu, K. M., Qiu, D. Y., Shen, X. L., Li, X. H., and Wang, S. P. 2008. Isolation and manipulation of quantitative trait loci for disease resistance in rice using a candidate gene approach. Mol. Plant 1:786-793.
Hückelhoven, R., Dechert, C., and Kogel, K. H. 2003. Overexpression of barley BAX inhibitor 1 induces breakdown of mlo-mediated penetration resistance to Blumeria graminis. Proc. Natl. Acad. Sci. U.S.A. 100:5555-5560.

Ihlow, A., Schweizer, P., and Seiffert, U. 2008. A high-throughput screening system for barley/powdery mildew interactions based on automated analysis of light micrographs. BMC Plant Biol. doi:10.1186/1471-22298-6. Published online.

Jackson, B. N., Schnable, P. S., and Aluru, S. 2008. Consensus genetic maps as median orders from inconsistent sources. IEEE/ACM Trans. Comput. Biol. Bioinf. 5:161-171.

Jafary, H., Szabo, L. J., and Niks, R. E. 2006. Innate nonhost immunity in barley to different heterologous rust fungi is controlled by sets of resistance genes with different and overlapping specificities. Mol. Plant-Microbe Interact. 19:1270-1279.

Jafary, H., Albertazzi, G., Marcel, T. C., and Niks, R. E. 2008. High diversity of genes for nonhost resistance of barley to heterologous rust fungi. Genetics 178:2327-2339.

Jahoor, A., Eriksen, L., and Backes, G. 2004. QTL and genes for disease resistance in barley and wheat. Pages 199-251 in: Cereal Genomics. Kluwer Academic Publishers, Dordrecht, The Netherlands.

Jansen, R. C. 1993. Interval mapping of multiple quantitative trait loci Genetics 135:205-211.

Jansen, R. C., and Stam, P. 1994. High resolution of quantitative traits into multiple loci via interval mapping. Genetics 136:1447-1455.

Jeger, J., and Viljanen-Rollinson, S. L. H. 2001. The use of area under the disease-progress curve (AUDPC) to assess quantitative disease resistance in crop cultivars. Theor. Appl. Genet.102:32-40.

Jensen, M. K., Rung, J. H., Gregersen, P. L., Gjetting, T., Fuglsang, A. T., Hansen, M., Joehnk, N., Lyngkjaer, M. F., and Collinge, D. B. 2007. The HvNAC6 transcription factor: A positive regulator of penetration resistance in barley and Arabidopsis. Plant Mol. Biol. 65:137-150.

Johrde, A., and Schweizer, P. 2008. A class III peroxidase specifically expressed in pathogen-attacked barley epidermis contributes to basal resistance. Mol. Plant Pathol. 9:687-696.

Jones, J. D., and Dangl, J. L.2006. The plant immune system. Nature 444:323-329

Kelly, J. D., and Vallejo, V. A. 2005. QTL analysis of multigenic disease resistance in plant breeding. Pages 21-48 in: Multigenic and Induced Systemic Resistance in Plants. Springer, New York.

Kleinhofs, A., and Graner, A. 2001. An integrated map of the barley genome. Pages 187-199 in: DNA-Based Markers in Plants. Kluwer Academic Publishers, Dordrecht, The Netherlands.

Kleinhofs, A., Kilian, A., Saghai Maroof, M. A., Biyashev, R. M., Hayes, P., Chen, F. Q., Lapitan, N., Fenwick, A., Blake, T. K., Kanazin, V., Ananiev, E., Dahleen, L., Kudrna, D., Bollinger, J., Knapp, S. J., Liu, B., Sorrells, M., Heun, M., Franckowiak, J. D., Hoffman, D., Skadsen, R., and Steffenson, B. J. 1993. A molecular, isozyme and morphological map of the barley (Hordeum vulgare) genome. Theor. Appl. Genet. 86:705-712.

Koga, H., Bushnell, W. R., and Zeyen, R. J. 1990. Specificity of cell type and timing of events associated with papilla formation and the hypersensitive reaction in leaves of Hordeum vulgare attacked by Erysiphe graminis f. sp. hordei. Can. J. Bot. 68:2344-2352.

Kurth, J., Kolsch, R., Simons, V., and Schulze-Lefert, P. 2001. A high resolution genetic map and a diagnostic RFLP marker for the $M l g$ resistance locus to powdery mildew in barley. Theor. Appl. Genet. 102:53-60.

Lipps, P. E., and Madden, L. V. 1992. Effects of plot size and border width on assessment of powdery mildew of winter wheat. Plant Dis. 76:299303.

Manosalva, P. M., Davidson, R. M., Liu, B., Zhu, X., Hulbert, S. H., Leung, H., and Leach, J. E. 2009. A germin-like protein gene family functions as a complex quantitative trait locus conferring broad-spectrum disease resistance in rice. Plant Physiol. 149:286-296.

Marcel, T. C., Aghnoum, R., Durand, J., Varshney, R. K., and Niks, R. E. 2007a. Dissection of the barley 2L1.0 region carrying the 'Laevigatum' quantitative resistance gene to leaf rust using near isogenic lines (NIL) and subNIL. Mol. Plant-Microbe Interact. 20:1604-1615.

Marcel, T. C., Varshney, R. K., Barbieri, M., Jafary, H., de Kock, M. J. D., Graner, A., and Niks, R. E. 2007b. A high-density consensus map of barley to compare the distribution of QTL for partial resistance to Puccinia hordei and of defence gene homologues. Theor. Appl. Genet. 114:487-500.

Mastebroek, H. D., and Balkema-Boomstra, A. G. 1991. Identification of growth stage dependent expression of partial resistance of barley to powdery mildew. Euphytica 58:113-118.

Mesfin, A., Smith, K. P., Dill-Macky, R., Evans, C. K., Waugh, R., Gustus, C. D., and Muehlbauer, G. J. 2003. Quantitative trait loci for Fusarium head blight resistance in barley detected in a two-rowed by six-rowed population. Crop Sci. 43:307-318. 
Mitchell-Olds, T., and Schmitt, J. 2006. Genetic mechanisms and evolutionary significance of natural variation in Arabidopsis. Nature 441:947-952

Niks, R. E., and Marcel, T. C. 2009. Non-host and basal resistance: How to explain specificity? New Phytol. 182:817-828.

Parlevliet, J. E. 1983. Can horizontal resistance be recognized in the presence of vertical resistance in plants exposed to a mixture of pathogen races? Phytopathology 73:379.

Parlevliet, J. E., and van Ommeren, A. 1984. Interplot interference and the assessment of barley cultivars for partial resistance to leaf rust, Puccinia hordei. Euphytica 33:685-697.

Parlevliet, J. E., and van Ommeren, A. 1985. Race-specific effects in major genic and polygenic resistance of barley to leaf rust in the field: Identification and distinction. Euphytica 34:689-695.

Pflieger, S., Lefebvre, V., Caranta, C., Blattes, A., Goffinet, B., and Palloix, A. 1999. Disease resistance gene analogues as candidates for QTL involved in pepper-pathogen interactions. Genome 42:1100-1110.

Pflieger, S., Lefebvre, V., and Causse, M. 2001. The candidate gene approach in plant genetics: A review. Mol. Breed. 7:275-291.

Potokina, E., Druka, A., Luo, Z., Wise, R., Waugh, R., and Kearsey, M. 2008. Gene expression quantitative trait locus analysis of 16,000 barley genes reveals a complex pattern of genome-wide transcriptional regulation. Plant J. 53:90-101.

Prioul, S., Frankewitz, A., Deniot, G., Morin, G., and Baranger, A. 2004. Mapping of quantitative trait loci for partial resistance to Mycosphaerella pinodes in pea (Pisum sativum L.), at the seedling and adult plant stages. Theor. Appl. Genet. 108:1322-1334

Prioul-Gervais, S., Deniot, G., Receveur, E. M., Frankewitz, A., Fourmann, M., Rameau, C., Pilet-Nayel, M. L., and Baranger, A. 2007. Candidate genes for quantitative resistance to Mycosphaerella pinodes in pea (Pisum sativum L.). Theor. Appl. Genet. 114:971-984.

Qi, X., Stam, P., and Lindhout, P. 1998. Use of locus-specific AFLP markers to construct a high-density molecular map in barley. Theor. Appl. Genet. 96:376-384.

Qi, X., Jiang, G., Chen, W., Niks, R. E., Stam, P., and Lindhout, P. 1999. Isolate-specific QTL for partial resistance to Puccinia hordei in barley. Theor. Appl. Genet. 99:877-884.

Qi, X., Fufa, F., Sijtsma, D., Niks, R. E., Lindhout, P., and Stam, P. 2000. The evidence for abundance of QTL for partial resistance to Puccinia hordei on the barley genome. Mol. Breed. 6:1-9.

Read, B. J., Raman, H., McMichael, G., Chalmers, K. J., Ablett, G. A., Platz, G. J., Raman, R., Genger, R. K., Boyd, W. J. R., Li, C. D., Grime, C. R., Park, R. F., Wallwork, H., Prangnell, R., and Lance, R. C. M. 2003. Mapping and QTL analysis of the barley population Sloop $\times$ Halycon. Aust. J. Agric. Res. 54:1145-1153.

Rostoks, N., Mudie, S., Cardle, L., Russell, J., Ramsay, L., Booth, A., Svensson, J. T., Wanamaker, E. M., Hedley, P. E., Liu, H., Morris, J., Close, T. J., Marshall, D. F., and Waugh, R. 2005. Genome-wide SNP discovery and linkage analysis in barley based on genes responsive to abiotic stress. Mol. Genet. Genomics 274:515-527.

Saari, E. E., and Prescott, J. M. 1975. A scale for appraising the foliar intensity of wheat disease. Plant Dis. Rep.59:377-380.

Sato, K., Hori, K., and Takeda, K. 2008. Detection of Fusarium head blight resistance QTL using five populations of top-cross progeny derived from two-row $\times$ two-row crosses in barley. Mol. Breed. 22:517-526.

Schonfeld, M., Ragni, A., Fischbeck, G., and Jahoor, A. 1996. RFLP mapping of three new loci for resistance genes to powdery mildew (Erysiphe graminis f sp hordei) in barley. Theor. Appl. Genet. 93:48-56.

Schweizer, P. 2007. Nonhost resistance of plants to powdery mildew-new opportunities to unravel the mystery. Physiol. Mol. Plant Pathol. 70:3-7.

Schweizer, P., Pokorny, J., Abderhalden, O., and Dudler, R. 1999. A transient assay system for the functional assessment of defense-related genes in wheat. Mol. Plant-Microbe Interact. 12:647-654.

Shtaya, M. J. Y., Marcel, T. C., Sillero, J, C., Niks, R. E., and Rubiales, D. 2006. Identification of QTL for powdery mildew and scald resistance in barley. Euphytica 151:421-429.

Spaner, D., Shugar, L. P., Choo, T. M., Falak, I., Briggs, K. G., Legge, W. G., Falk, D. E., Ullrich, S. E., Tinker, N. A., Steffenson, B. J., and
Mather, D. E. 1998. Mapping of disease resistance loci in barley on the basis of visual assessment of naturally occurring symptoms. Crop Sci. 38:843-850.

Stein, N., Prasad, M., Scholz, U., Thiel, T., Zhang, H., Wolf, M., Kota, R., Varshney, R. K., Perovic, D., Grosse, I., and Graner, A. 2007. A 1,000loci transcript map of the barley genome: New anchoring points for integrative grass genomics. Theor. Appl. Genet. 114:823-839.

Thomas, W. T. B., Powell, W., Waugh, R., Chalmers, K. J., Barua, U. M., Jack, P., Lea, V., Forster, B. P., Swanston, J. S., Ellis, R. P., Hanson, P. R., and Lance, R. C. M. 1995. Detection of quantitative trait loci for agronomic, yield, grain and disease characters in spring barley (Hor deum vulgare L.). Theor. App.1 Genet. 91:1037-1047.

Trujillo, M., Troeger, M., Niks, R. E., Kogel, K. H., and Hückelhoven, R. 2004. Mechanistic and genetic overlap of barley host and non-host resistance to Blumeria graminis. Mol. Plant Pathol. 5:389-396.

Van Ooijen, J. W. 2004. MapQTL Version 5, Software for the Mapping of Quantitative Trait Loci in Experimental Populations. Kyazma BV. Wageningen, The Netherlands.

Varshney, R. K., Marcel, T. C., Ramsay, L., Russell, J., Röder, M., Stein, N., Waugh, R., Langridge, P., Niks, R. E., and Graner, A. 2007. A high density barley microsatellite consensus map with 775 SSR loci. Theor. Appl. Genet. 114:1091-1103.

Vidhyasekaran, P. 2003. Bacterial disease resistance in plants. In: Molecular Biology and Biotechnological Applications. Haworth Press, Binghampton, NY, U.S.A.

Von Korff, M., Wang, H., Leon, J., and Pillen, K. 2005. AB-QTL analysis in spring barley. I. Detection of resistance genes against powdery mildew, leaf rust and scald introgressed from wild barley. Theor. Appl. Genet. 110:583-590.

Voorrips, R. E. 2002. MapChart: Software for the presentation of linkage maps and QTL. J. Hered. 93:77-78.

Wang, Z., Taramino, G., Yang, D., Liu, G., Tingey, S. V., Miao, G. H., and Wang, G. L. 2001. Rice ESTs with disease-resistance gene- or defenseresponse gene-like sequences mapped to regions containing major resistance genes or QTL. Mol. Genet. Genomics 265:302-310.

Wenzl, P., Li, H., Carling, J., Zhou, M., Raman, H., Paul, E., Hearnden, P., Maier, C., Xia, L., Caig, V., Ovesná, J. Cakir, M., Poulsen, D., Wang, J., Raman, R., Smith, K. P., Muehlbauer, G. J., Chalmers, K. J., Kleinhofs, A., Huttner, E., and Kilian, A. 2006. A high-density consensus map of barley linking DArT markers to SSR, RFLP and STS loci and agricultural traits. BMC Genomics. doi:10.1186/1471-2164-7-206. Published online.

Zhan, J., Fitt, B. D. L., Pinnschmidt, H. O., Oxley, S. J. P., and Newton, A. C. 2008. Resistance, epidemiology and sustainable management of Rhynchosporium secalis populations on barley. Plant Pathol. 57:1-14.

Zhang, N. W., Lindhout, P., Niks, R. E., and Jeuken, M. J. W. 2009. Genetic dissection of Lactuca saligna nonhost resistance to downy mildew at various lettuce developmental stages. Plant Pathol. 58:923-932.

Zhu, M., and Zhao, S. 2007. Candidate gene identification approach: Progress and challenges. Int. J. Biol. Sci. 3:420-427.

Zierold, U., Scholz, U., and Schweizer, P. 2005. Transcriptome analysis of mlo-mediated resistance in the epidermis of barley. Mol. Plant Pathol. 6:139-152.

Zimmermann, G., Baumlein, H., Mock, H. P., Himmelbach, A., and Schweizer, P. 2006. The multigene family encoding germin-like proteins of barley. Regulation and function in basal host resistance. Plant Physiol. 142:181-192.

\section{AUTHOR-RECOMMENDED INTERNET RESOURCES}

dCAPS Finder: helix.wustl.edu/dcaps/dcaps.html

Grain Genes database: wheat.pw.usda.gov

MQConvert JoinMap 4: www.kyazma.nl

National Center for Biotechnology Information website: www.ncbi.nlm.nih.gov

Oregon State University Barley Project: www.barleyworld.org

PIEXdb (Plant Expression database): www.plexdb.org/index.php 